\title{
THE JAPANESE UNDERSTANDING ON NEW WORDS WITH SUFFIX -TEKI ACROSS GENERATIONS
}

\author{
Teresa Angelina Kaluge* \\ Department of Japanese Studies, Airlangga University \\ Jl. Airlangga No. 4 - 6, Surabaya, Jawa Timur 60115, Indonesia \\ teresa.angelina.k@fib.unair.ac.id
}

Received: $01^{\text {st }}$ August 2020/Revised: $24^{\text {th }}$ August 2020/Accepted: $14^{\text {th }}$ September 2020

How to Cite: Kaluge, T. A. (2020). The Japanese understanding on new words with suffix -teki across generations.

Lingua Cultura, 14(2), 171-178. https://doi.org/10.21512/lc.v14i2.6604

\begin{abstract}
The research attempted to portray the language dynamic on using the suffix -teki among Japanese based on old and young generations as reflected by age. Data were collected by using questionnaires distributed to the Japanese native speakers. New words were responded to as understandable, doubtful, and difficult. Descriptive and inferential statistical analyses were used in order to find out the results. For both the young and old generations, the stem words from Kango were the easiest to understand, yet, the most difficult words were groups of Gairaigo, Wago, and Konshugo. A significant difference was found between the age groups. The old generation expressed more doubt on new foreign words than the young one only in using -teki for Gairaigo word group. It is concluded that some meanings of words with suffixes are understood across young and old generations. However, the development of technology and globalization may impact some doubtful responses that differentiate between these two generations.
\end{abstract}

Keywords: new word understanding, Japanese suffix -teki, Japanese generations

\section{INTRODUCTION}

Language and culture have various relations of meaning and interpretation according to the content of its discussion (Sutjiati \& Rasiban, 2018). Some people view both as being subordinate, where the language is part of the culture. However, others see it as having a coordinative relation, considering language and culture as equal and equivalent. Another opinion places the two as important components that interact in society. The research considers all three types of relationships by raising the case of a suffix in Japanese from the lens of native speakers of different generations, i.e., young and old.

A word is a part of language as well as a small unit of a sentence. Through a word, communication between certain language users can be established. There are several ways of forming a word, and one of them is through giving suffixes. Suffix gives a certain meaning to the created word. The suffix is one of the main components in almost all languages. For Japanese itself, there are various prefixes and suffixes with diverse functions. One example is the suffix -teki that has a variety of definitions (Otsuka, 2019). A suffix -teki could define 'like', 'has the characteristics of', or 'related to' the stem word (Mochizuki, 2010; Takahashi, 2005). The newly created words from -teki itself would always be classified as an adjective-noun (Jin, 2012; Yashima, 2019).

The suffix -teki is unique in many ways with unusual characteristics compared to other suffixes in general. A suffix usually has a restriction for the stem words, only permit an adjective, for example, but for -teki, various kinds of nouns, from Kango, Wago, Gairaigo, to sentences are possible (Endō, 1984; Takahashi, 2005). Thus, this suffix has been widely known to easily create new words (Mochizuki, 2010; Yashima, 2019). Young Japanese started this trend by the year 2000, when they combined a noun watashi 'I' with -teki to create a totally new Japanese word watashi -teki 'related to me/me-like', often in expressing self-opinion without considering the correctness of Japanese grammar (Harada, 2017; Mochizuki, 2010). However, it is sometimes redundant for an adjective to be a stem word for-teki because the result would be another adjective-noun unless the adjective stem word 
itself has another characteristic of a noun (Takahashi, 2005).

Japanese vocabulary classification based on its origin is called Goshu. It consists of four types, namely, Kango, Wago, Gairaigo, and Konshugo (Harada, 2016; Kaji, 2018; Kenki, 2018; Kondō, 2017; Ogura, 2017). Kango is a Japanese vocabulary derived from Chinese and is generally written using Japanese Kanji. Wago is an authentic Japanese vocabulary created without the influence of a foreign language. Gairaigo is a vocabulary formed from foreign languages, except Chinese. Gairaigo can be formed from the uptake of English or other foreign languages. Konshugo is a vocabulary formed from the combination of the other three Goshu, such as the merger of Wago and Kango, Kango and Gairaigo, or Wago and Gairaigo. These four kinds of Goshu are all acceptable as the stem word for -teki (Jin, 2012; Takahashi, 2005).

Studies on -teki, have been done in Japan for a long time ago. The first was done by Endō in 1984, who looked for examples of new words suffixed -teki in various written media, such as newspapers, magazines, and essays. His findings were then matched with three Japanese dictionaries, and among the words, only the vocabulary found in all three dictionaries was examined. The aim was to find vocabulary acknowledged in the dictionary and lessen the number of Japanese language learners' errors from Chinese language background. For suffix -teki is not used only in Japanese, but also in Chinese, yet with a different pronunciation. It is revealed that some vocabularies are not found suffixed -teki, and those are semantically classified as words with the meaning of social statuses, such as family relations, and young and old (Endō, 1984). Even though he did not examine Goshu as the stem words, Endō (1984) found in newspapers, magazines, and essays that Kango, Gairaigo, phrases, sentences, and even proverbs could have suffixed -teki.

Endo (1984) is not the only researcher compared -teki in written media. Jin (2012) has also conducted a study on -teki but by using the internet as the data source. He has searched for examples of sentences suffixed -teki, then compared it with vocabularies suffixed -teki na (the latter is commonly used by the young Japanese). Similar to Endō (1984), Jin (2012) does not specifically examine Goshu suffixed -teki, but he has found various types of vocabulary as stem words for -teki, ranging from Goshu (Kango, Wago, Gairago, and Konshugo) to words, phrases, and even sentences.

In the last five years, there has been an increasing number of studies examining the suffix -teki (Harada, 2015, 2016, 2017; Kaji, 2018; Kenki, 2018; Otsuka, 2019; Wang, 2016; Yashima, 2019). Some of them specifically analyzed -teki and -teki na, which have different nuance. Although both used -teki, the usage of -teki na softens the impression of the words spoken (Jin, 2012). Also, -teki na is followed by more variety of Goshu, in comparison to -teki (Harada, 2015). Kenki (2018) has analyzed Goshu as the stem words for -teki, together with other eight suffixes. For -teki, the dominant stem words are Kango. On the other hand, there is only one or no Wago, Gairaigo, and Konshugo has a suffix -teki (Kenki, 2018).

Kagoshima in Otsuka (2019) has discussed the vocabulary suffixed -teki and compared its acceptance between the Japanese junior and senior high school students. Comparisons are per some words, so it is not a representative result for all words suffixed -teki. Interestingly, although -teki is known to easily create new vocabularies, not all the newly created words are equally accepted by all Japanese native speakers. Some words like ippanteki are accepted by the majority, but most of them view mokuhyōteki as unacceptable, despite both ippan and mokuhyō are Kango. New words created by -teki have been shown to have increased both in daily usage and in official written media like Japanese dictionaries (Wang, 2016). However, it is important to note some differences between what is expressed by native speakers with foreigners learning the Japanese language (Mochizuki, 2010). Despite the various perspectives used in studying this suffix have been done, so far, no one has examined how native speakers perceive the new vocabulary created by this suffix with all Goshu as the stem words.

The suffix -teki is popularized by Japanese young people (Harada, 2017; Mochizuki, 2010). However, the way older Japanese perceive new words created by this suffix, whether they have the same understanding with the young people, has not been studied yet. Following the recent development, the research would like to find out whether Japanese understanding of the stem words combined with -teki also varied or not. The difference between this research and previous research is that first, the internet is used to find initial data sources. Second, the research focuses on an understanding based on Goshu suffixed -teki, which are not much focused in previous studies. The research uses age as an independent variable, considering that this has not been found in previous studies. Therefore, the research tries to answer two main research questions, namely (1) what is the description of the understanding of suffix -teki based on Goshu as the stem words, and (2) are there any differences in understanding words suffixed -teki by the Japanese people based on their age?

In relation to the proposed research questions, the research contains two objectives. The first is to know the description of the suffix -teki based on the stem words. The second is to find out the similarities and differences in understanding suffixes -teki between the young and the old generation. The research's expected benefits are to help Japanese learners in learning and understanding the suffix -teki deeper, viewed from the stem words. Thus, the reader can use this suffix directly in conversation and writing, both when communicating directly with Japanese people or vice versa. It is also enabling the Japanese culture and language observers to choose certain words to be compared with Indonesian. 


\section{METHODS}

The research is designed through the following steps. First, new words suffixed -teki are collected from the internet using the Google search engine. At this stage, the stem words are classified too based on Goshu. At first, there are 1.121 words collected. These words are reduced by re-checking the stem words and those new words suffixed -teki in the three Japanese dictionaries, namely the Gyakubikijiten dictionary, the Gyakubikijiten electric dictionary, and the $7^{\text {th }}$ edition of the Shinmeikai Kokugo Daijiten dictionary (Yamada et al., 2012) based on two principles. First, if the new word suffixed -teki has already appeared on the dictionary, then it would be excluded from the research. Second, whether the stem words are listed in the dictionary. If only one of the principles above applied to the vocabulary, it would be excluded from the research.

From the selection of the initial research, 502 words are used in the research. Those are new vocabularies not available yet in the three JapaneseJapanese vocabularies. Based on the Goshu, the entire vocabularies consist of 300 Kango, 67 Wago, 122 Gairaigo, and 13 Konshugo. All these vocabularies are used in the questionnaire as the research instruments. The 502 words are divided into eight questionnaire files; each consisted of 61-63 words. Although divided into eight parts, each respondent has to answer all the 502 words. Using a questionnaire is not a new thing for analyzing -teki, as Harada (2016) has also used one, except the questions focused more on comparing -teki and -teki na. The elements in the research questionnaire are basic information about gender, age, vocabulary items (with and without -teki) accompanied by three choices for each of the vocabulary (understandable, doubtful, and difficult to understand).

The questionnaires are distributed within the area of Hiroshima University campus in the suburb of Saijo, together with Nishitakaya, and Hiroshima city. Some of the participants answer the 502 words immediately, while some others take it home and return the answers several days later. All participants are given time between two to three weeks to finish their answers. Time is given due to the enormous number of words that have to be answered. All respondents are randomly selected for filling out the instruments. From a total of 60 people, 34 provides the full answers. Thus, only data received from those 34 participants are analyzed. In terms of age, 17 respondents aged 19-30 years (young group) consist of 8 men and 9 women. The remaining 17 respondents are aged 40-80 years, consisting of 7 men and 10 women, and are considered old.

Data collected from the questionnaires are then processed statistically to answer the research questions. The analysis utilized is descriptive and inferential statistics (Field, 2017; Aldrich, 2019). Descriptive analysis is used to describe the understanding of the new vocabularies in this research. At the same time, the inferential statistics of the t-test is used to examine whether there is a difference in understanding between the young and old groups.

\section{RESULTS AND DISCUSSIONS}

The findings are presented in two age groups, namely young (19-30 years old) and old (40-80 years old). Description of Kango, Gairaigo, Wago, and Konshugo are presented by looking at each age group in all three categories of understanding. First, the description of understanding Kango with the suffix is shown in Figure 1. Overall, the highest average is in Kango-understandable answer. Both age groups have an average of $50 \%$ and above. The young group has a slightly higher average of $53 \%$, with a $3 \%$ average difference from the old group. Next is the Kangodoubtful answer. Both groups' ratings are equally below $20 \%$. The old group has a higher average of $17 \%$, while the young group with an average of $13 \%$. The percentages indicate that the two groups do not have sufficiently high doubts when they find the Kango suffixed -teki.

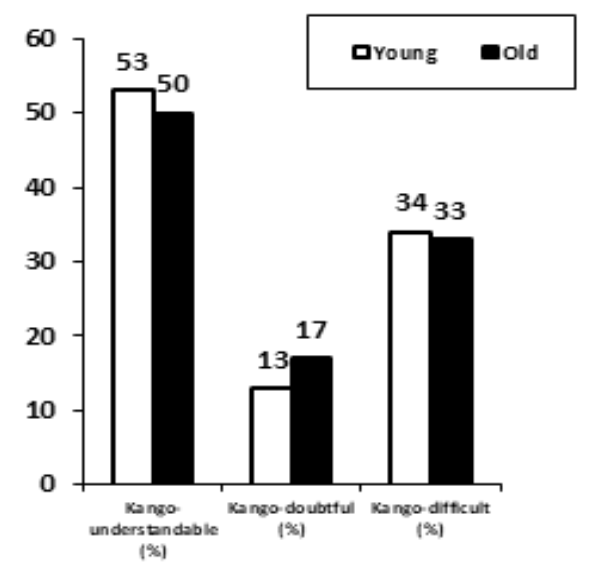

Figure 1 Understanding of Kango Suffixed -teki

In Kango-difficult, the average of the two groups is $33 \%$ and $34 \%$, and the young group has an average of $34 \%$. The average Kango-difficult is still below the average Kango-understandable, but slightly higher than Kango-doubtful. There is a tendency of having difficulty understanding Kango with -teki, but the possibility is still below $50 \%$. Sometimes Kango with -teki could cause a sense of difficulty for any age group.

In contrast to Kango, the understanding of the Gairaigo word group that has -teki is shown in Figure 2. Overall, the highest average is in the Gairaigodifficult answer. Both the young and old groups have experienced difficulties when dealing with the Gairaigo suffixed-teki, where the young group appears to have more difficulties (average 58\%) than the elderly. In terms of Gairago-understandable answer, the old group has a higher average of $33 \%$, only $1 \%$ difference from the young group. Gairaigo originates 
from foreign languages, and the number continues to grow as more foreign words enter Japan. In general, the young generation is the one who accepts changes easily, including new foreign vocabularies. However, this data contradicted that general opinion.

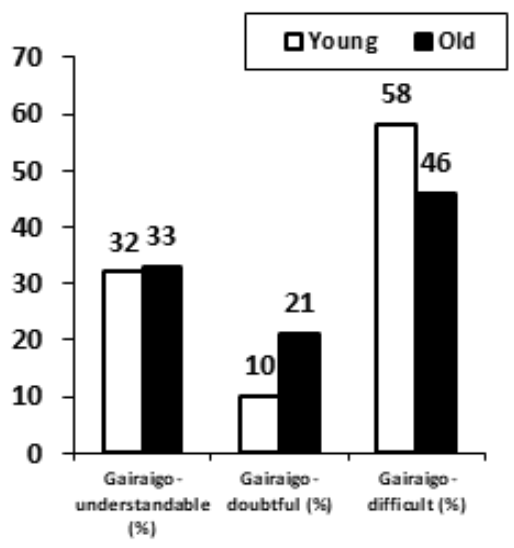

Figure 2 Understanding of Gairaigo Suffixed -teki

Regarding Gairaigo-doubtful, the old group has a higher level of doubt than the young group, as evidenced by an average of $21 \%$. The young group, however, has $10 \%$, and the difference is $11 \%$. Doubts could arise for middle and upper age groups when they encounter new words considered less prevalent in their generation. This is possible because Gairaigo is a foreign vocabulary absorbed into Japanese.

The understanding of the Wago word group with -teki is illustrated in Figure 3.

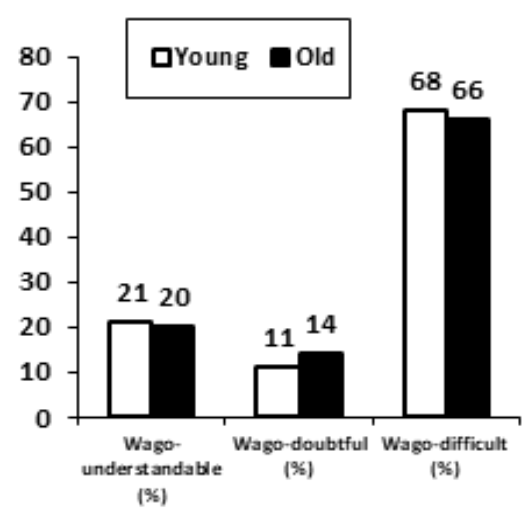

Figure 3 Understanding of Wago with -teki

Like Gairaigo, Wago's highest average also demonstrates in Wago-difficult answers. Both groups have experienced similar difficulties, with an average above $50 \%$. Only the young group has a slightly higher average of $68 \%$, and the average difference is only $2 \%$. Regarding Wago-understandable, the results show that the understanding level of the two groups is at approximately the same degree, around $20 \%$, the difference is only $1 \%$. Meanwhile, the young group has a higher average of $21 \%$. For the Wago-doubtful answer, the average of the two groups is below $20 \%$. It could be concluded that the tendency of doubtful answers is not too high. The old group has a higher average of $14 \%$, followed by the young group, with an average of $11 \%$.

Figure 4 presents an understanding of Konshugo suffixed -teki based on the age group. Similar to Gairaigo and Wago, the highest average is in Konshugo-difficult answers with a mean above 50\%. The young group seems to have more difficulty with an average of $68 \%$. For Konshugo-understandable answer, the old group has a higher average of $26 \%$, only $2 \%$ higher than the young group.

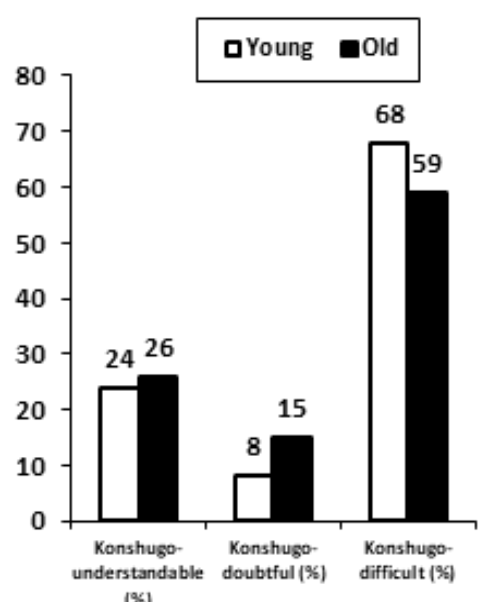

Figure 4 Understanding of Konshugo Suffixed -teki

Next is Konshugo-doubtful. The old group has a higher average of $15 \%$ compares to the young group. The average difference is $7 \%$. Of all the Goshu word classes, only Kango has the highest average of 'understandable' answers. Other word classes, such as Wago, Gairaigo, and Konshugo, actually have the highest average on 'difficult' answers.

The results of inferential data analysis that examined differences between the young and the old generations are summarized and sorted according to the four classes of Goshu words. The results of the t-test are summarized in Table 1, which detailed the Kango, Gairaigo, Wago, and Konshugo. The t-value proves that the mean data between the two generations do not differ significantly ( $>0,05)$. The same thing happens to the new words of the Wago, and Konshugo with new words that are easily understood, doubted, or considered difficult to express by the two generations without significant differences.

However, the data in Gairaigo show differently. There are a number of words stated to be easily understood accurately by young and old respondents. Likewise, a number of new words are still said to be difficult to understand by both generations. However, in expressing doubts about a number of vocabulary words, statistics reveal significant differences between generations. The t-value of the data also prove that 
there is a significant difference $(p=0,042<0,05)$ between young and old generation when doubting a number of new vocabulary words. The old group has a higher level of doubt than the young one. This finding might express how dynamic the doubt among both groups of participants.

Table 1 A Summary of T-Test Results

\begin{tabular}{lcc}
\hline \multirow{2}{*}{\multicolumn{1}{c}{ Variable }} & \multicolumn{2}{c}{ T-Test } \\
\cline { 2 - 3 } & T & Sig \\
\hline Kango-understandable & 0,51 & 0,615 \\
Kango-doubtful & $-1,0$ & 0,281 \\
Kango-difficult & 0,12 & 0,904 \\
Garaigo-understandable & $-0,20$ & 0,841 \\
Garaigo-doubtful & $\mathbf{- 2 , 1 6 *}$ & $\mathbf{0 , 0 4 2}$ \\
Garaigo-difficult & 1,16 & 0,254 \\
Wago-understandable & 0,23 & 0,821 \\
Wago-doubtful & 1,07 & 0,293 \\
Wago-difficult & 0,31 & 0,761 \\
Konshugo-understandable & $-0,35$ & 0,728 \\
Konshugo-doubtful & $-1,90$ & 0,067 \\
Konshugo-difficult & 1,23 & 0,229 \\
\hline Notes: Significantdiffer & &
\end{tabular}

Notes: * Significant difference between generations

The old group ages are ranged between 4080 years. That said, the suffix -teki used today is not based on the correct use of grammar. Initially, it is younger Japanese people who popularized the usage of -teki (Harada, 2017; Mochizuki, 2010). Due to the increasing number of users, -teki begins to be recognized and used widely. Nonetheless, -teki is not a suffix used in the generation of middle to upper age groups. This might be the reason behind the hesitation of the 40-80-years age group in answering. They may have understood the stem word meaning, but because they feel that the new word suffixed -teki is not used by people their age, they become doubtful. In addition, it should be noted once again that Gairaigo is an uptake of a foreign language. Certainly, the number continues to grow over time. Those who do not master the new vocabulary might find it difficult to understand. This could be why the middle and upper age groups' doubts when facing Gairaigo with -teki. For example, a word サポーター的 sapōtāteki has mean ratings from the young group as $75 \%$ difficult, and $12,5 \%$ doubtful. However, the old group means ratings for this word are $47,1 \%$ doubtful, $29,4 \%$ difficult, and $23,5 \%$ understandable. Sapōtà is a Gairaigo word derived from the English vocabulary 'supporter', although it is not clear the possible meaning of this new word suffixed-teki. In this case, although the combination of sapōtā and -teki might seem confusing and difficult to understand, the old group prefers to answer 'doubtful' (47,1\%) over 'difficult' $(29,4 \%)$.

The research is begins with the discovery of several Japanese vocabularies that are not well known at the time of collecting data. They appear on the internet but are not necessarily understood in the wider community. It is found no less than 1000 new vocabulary suffixed -teki. Although -teki is already known for creating new words easily (Yashima, 2019), these results reflect how rapidly new words appear from time to time. The development of any new words could emerge gradually, like -teki that created 13 new vocabularies in 1898 to new 450 new words in 2008 . All are officially recognized in the Japanese dictionary (Wang, 2016). This number certainly does not include new words developed among daily conversation or written media such as magazines, newspapers, and internet websites. Similar to Japan, Indonesia also has and is experiencing a similar development. In the ongoing third millennium period, with the breakthrough of globalization across the globe, language life can develop even more dynamically and bring several inevitable consequences.

The results of descriptive statistics reveal that related to the inclusion of suffix -teki in Japanese. The easily understood vocabularies are created from Kango as the stem word, which is an uptake of Chinese. Although this does not seem a novel finding, as Kaji (2018) has already noted, comparing all the Goshu, -teki is suitable for having Kango as stem word, except that the research does not consider age as the variable. Thus, in the research, a similar result is demonstrated by both generations, young and old. Given the historical point of view, some Japanese vocabularies are originated from the influence of its neighbors' cultural environment (Chinese and Korean). Thus, this finding is very reasonable if Japanese speakers maintain and still understand that aspect well. Although some Kango is considered difficult to understand when suffixed -teki, it might be due to these new words' unfamiliarity. For example, in the research, $100 \%$ of the young group regards 紹 介的 shōkaiteki as 'difficult', while on the other hand, answers in the old group is varied (82,4\% 'difficult' and $17,6 \%$ 'doubtful'). Nevertheless, both groups view 基礎的' kisoteki' as 'understandable' (mean above $85 \%$ ), despite both shōkai and kiso are both Kango. Shōkai means 'introduction', and kiso means 'foundation'/'basis'. Thus, kisoteki is regarded as more familiar than shōkaiteki for both groups. Kango itself undergoes changes through some Japanese era, in which some become more familiar in the Japanese conversation and some still used in written Japanese (Konno, 2017). Similar to the experience of Indonesia, although it is influenced by various foreign languages, the Malay language (Aziz et al., 2017; Niess, 2016), which is the forerunner of the unifying language, is still used and understood well.

The new words suffixed -teki that considered difficult for most native speakers in Japan, both young 
and old, mostly have stem words from Gairaigo, Wago, and Konshugo. For example, in Wago, there is 全 <的 mattakuteki that perceived $100 \%$ difficult by both the young and old group. Mattaku is an adverb that defines 'completely', 'truly'. In Konshugo, there is エネル ギ一面的 enerugiimenteki that perceived as difficult by both the young $(81,3 \%)$ and old group $(70,6 \%)$ as well. Enerugiimen is a combination of Gairaigo (enerugii means 'energy') and Kango (men means 'face'/'surface'). These results are in line with Kenki (2018). These three groups of Goshu words reflect absorption words from western languages, current Japanese, and a combination of both. This difficulty may reflect that if something new is not necessarily understood on its own, it still needs to be adjusted and understood gradually. Although young people tend to be divergent or get out of the establishment by using new vocabulary, it is not necessarily immediately well understood by their fellow colleagues. Another possible reason is some words could naturally be accepted as having other suffixes like $-s a$, $-s e i$, for example, rather than -teki (Kaji, 2018).

Thus, the next question is, if previous research (Kenki, 2018) has already found only Kango are mostly suffixed -teki, then where from and for what purpose the other Goshu has suffixed -teki and why those were available on the internet? Like the trend of watashi-teki that happened in 2000 (Harada, 2017; Mochizuki, 2010), the young Japanese could have been made, although no evidence has directly stated it.

The significant finding of the research is the doubt in understanding new words absorbed from western languages, especially English. This finding seems to prove language as a mirror of a generation (Severin, 2017). Older users are more hesitant to understand the meaning of new vocabulary than the younger generation. The younger generation's presence in this research expected to be born in the 1980s-1990s is bringing social change due to the influence of technology access (computers, cell phones, and other similar gadgets) in their lives. Their presence, along with the explosion of digital technology, has been able to make collaboration to care about problems in society. This phenomenon has an impact on how to communicate and speak globally. This finding suggests the same symptoms so that the differences between generation Y (young) and generation X (old) begin to appear. For the next decade, it is estimated that this difference can be increasingly clear and striking.

Language always grows and develops according to the times. It grows and develops if there is a dynamic in its vocabulary and becomes stunned if there is no movement in its vocabulary. Language is like a tree, and leaves are the vocabulary. If the tree grows, of course, there will always be new leaves that grow, and inevitably, there are also yellow leaves that wither and fall. Everything turns, likewise, vocabulary in developing languages. There will always be new vocabulary; there may also be old vocabulary forgotten and not used by the user. That is the life of language. Suffix, too, could undergo changes. An example is -hashi, a suffix frequently used in the old Japanese, but then declined as lesser people used it (Murayama, 2019). Another example is how handbook changes its content does impact a generation's understanding of vocabularies (Narikawa, 2017). Some words could be familiar to the older generation, but not for the young group and vice versa. In this case, the suffix -teki gets popularized by the younger Japanese generation, is still developing now. However, not all of the new words might be necessarily understood by the older Japanese. For example, findings from Otsuka (2019) that varieties might persist in native Japanese elementary school children's understanding of vocabularies suffixed -teki. The reason is partially that the definition of the suffix -teki in their dictionary varies. Some have a full explanation, others only have a simple definition, yet the suffix -teki is available in their workbook that sometimes differed from their dictionary (Otsuka, 2019).

Age does play a role in language usage, especially acquiring the native language (Inaba, 2018). In Japanese itself, when teenagers start to become in the twenties to thirties, they start to neglect some of their young people's language (Bankawa, 2020; Haristiani \& Putri, 2018). Although, as they age, the Japanese still consider themselves learning their native language (Kawasaki, 2017). Thus, it is not surprising to find different answers between participants from the same or different age group.

It is important to preserve the usage of Goshu. Kango is important to know the root of some Japanese words, and Wago is essential to know the richness of original Japanese words (Kawauchi, 2016). Although in written media, like magazines, Kango becomes lesser found, and Wago emerges significantly or vice versa (Kondō, 2019; 2017). Both younger and older generations need to preserve the words by using them in daily conversation or as the written language. The dynamics of language occur everywhere without distinguishing the origin of culture, geographical location, or ethnicity of the speakers (Tajeddin \& Ghaffaryan, 2020). In general, the findings of the research reflect the life of a language in one of the East Asian countries that are capable of producing new vocabulary through absorption from outside and within its environment. That indicates that the language is developing and very dynamic.

At present, most languages experience dynamics in the midst of globalization that has plagued various aspects of life (Valdez \& Flores, 2019). The dominance of developed industrial countries is enormous in the process of globalization. People can watch entertainment (films, music, and cultural activities) originating from western cultures that are different from eastern cultures, access films or news about world figures, and so on through the media. From these media, foreign lifestyles and cultural values are absorbed into consciousness. In the context of language dynamics, the phenomenon of globalization leads people to various possibilities, extremely positive or extreme negative, or various 
variations in their midst. Such contemporary meaning has not yet been the focus of the research.

The globalization era is full of charm and offers a lot of convenience to life, both through mass media such as television, magazines, and online media. In Japanese, too, the increased use of Gairaigo cannot be separated from the role of globalization (Raversa \& Haristiani, 2020). In addition, Gairaigo is often associated with a modern, sophisticated image, so it is not surprising that young people also start using it. When compared with Indonesia in the last decade, regional languages are threatened with extinction (Nurrochsyam, 2015; Sitokdana, Tanone, \& Tanaem, 2019). Many factors cause language to become extinct (Sitokdana, Tanone, \& Tanaem, 2019), including the factors of globalization and nationalism. The globalization factor is in the form of the threat of displacing the national language by English. Preservation of language and culture is absolutely necessary because the community has the right to preserve and maintain their language and culture. The same symptoms are also present in Japanese culture and language but have not been supported by valid evidence in the research.

The younger generation has a duty to preserve and maintain the use of their language by using it in daily conversation so that the language would not become extinct (Ortega, 2020). However, besides using the correct language, the younger generation tends to act and do something divergent or deviates from publicity and make new breakthroughs. Japan, as one of the developed countries where quite a number of young generation globalized globally, the idea of preserving its own language becomes a unique challenge. The use of suffixes is also appropriate to be taught to Japanese language learners (Harada, 2017). Because these suffixes easily produce new vocabulary, the vocabulary that has been officially recognized should be introduced first to students. The suffix -teki can be followed by various modifiers, producing only -teki, -teki na, -teki da, and others (Harada, 2017). This is not easy, but it does not mean impossible because, in reality, the traditional language and culture in Japan are still preserved until today.

\section{CONCLUSIONS}

The conclusions are drawn based on three choices, namely understandable, doubtful, and difficult. There are two conclusions drawn from the findings of the research. First, the understanding of both the young and the old generations are high for the Kango with -teki. The word classes Gairaigo, Wago, and Konshugo that have -teki are generally classified as difficult to understand by the native speakers. Second, doubts in understanding the words of Gairaigo that generally come from the west show a significant difference between the old and the young people. The young group seems more permissive than old participants.
The findings and discussions of the research imply four suggestions for the future. First, to consider carefully the formalization of vocabulary that has sprung up from time to time. If it meets the rules of the language, it is time to edit and record it into a dictionary that has been circulating in the form of the latest edition. Second, young people who tend to be more progressive and crash into established language structures are commonplace and should be given a place to express and innovate in various forms. Third, for Japanese language learners to be aware of and recognize the dynamics of everyday language that develops and has the opportunity to give a unique nuance in society. Fourth, for future research, the format of it could be replicated for variations in new vocabulary opportunities that are developing with larger samples to reflect more reasonable population parameters with smaller error opportunities. In addition, variations in the meaning of words in terms of expansion vs. narrowing and adaptation vs. amelioration, the effects of globalization, and various effects of the media today might be examined through research as well.

\section{ACKNOWLEDGEMENT}

I would like to thank Associate Professor Kanetaka Fukami from Morito Institute of Global Higher Education, Hiroshima University for the suggestions in conducting this study. Also, all the participants for the cooperation.

\section{REFERENCES}

Aldrich, J. O. (2019). Using IBM SPSS statistics: An interactive hands-on approach. California: Sage Publications Inc.

Aziz, Z., Yusuf, Y., Nasir, C., \& Masyithah, C. (2017). Cross-linguistic influences of Malay through cartoons on Indonesian children's language use in the home domain. Indonesian Journal of Applied Linguistics, 7(2), 339-348. https://doi.org/10.17509/ ijal.v7i2.8135.

Bankawa, T. (2020). Sedaibetsu dansei fasshon zasshi ni miru gengoteki tokuchō. Kanazawa Daigaku Ningen Shakaigakuiki Keizaigakurui Shakai Gengogaku Enshü Ronbunshū, 15, 113-125.

Endō, O. (1984). Setsubiji "teki” no imi to yōhō. Nihongo Kyōiku, 53, 125-138.

Field, A. (2017). Discovering statistics using IBM SPSS statistics. London: Sage Publications Ltd.

Harada, T. (2015). A study on the Japanese suffix teki - from the example of dansei-teki (na) and josei-teki (na). Dōshisha Daigaku Nihongo Nihon Bunka Kenkyū, 13, 45-70.

Harada, T. (2016). A study on the usage of suffixes teki and tekina: When they are used as adnominal modifiers. Bulletin of Center for Japanese Language and Culture, 14, 1-27. 
Harada, T. (2017). A study on the suffix teki through an analysis of distribution in its usage as an adnominal modifier, adverbial modifier and predicate word. Bulletin of Center for Japanese Language and Culture, 15, 17-37.

Haristiani, N., \& Putri, A. S. (2018). Japanese adverbs zenzen and mattaku: Pragmatic and sociolinguistic analysis. Advances in Social Science, Education, and Humanities Research, 257, 372-376. https://dx.doi. org/10.2991/icollite-18.2019.82.

Inaba, M. (2018). Developmental changes of MLU in Japanese and English language narratives. Bulletin of Aichi University of Education, 67(1), 47-55. https:// dx.doi.org/10.1177\%2F0142723713479436.

Jin, Y. Y. (2012). Teki ni kan suru ikkōsatsu. Hokkaidō Daigaku Daigakuin Bungaku Kenkyūka Kenkyū Ronshü, 12, 235-248.

Kaji, H. (2018). Nominalization and adjectivization by Japanese suffixes: -sa, -sei, -na, and -teki. ICU Working Papers in Linguistics (ICUWPL), 4, 29-40.

Kawasaki, A. (2017). Linguistic adulthood in Japanese. Language, Culture, and Communication: Journal of the College of Intercultural Communication, 9, 2952.

Kawauchi, A. (2016). Guidance of wago, kango, kairaigo. Gunma Daigaku Kyōiku Gakubu Kiyō Jinbun Shakai Kagakuhen, 65, 27-36.

Kenki, R. O. (2018). On the lexical limitations of preceding part of Sino-Japanese suffix. Bulletin of International Pacific University, 13, 37-45.

Kondō, A. (2017). Diachronic variation in modern Japanese literary text: Analysis based on etymological types ratios and part of speech ratios. In Proceedings of Language Resources Workshop. pp. 355-364.

Kondō, A. (2019). Goshuritsu hinshiritsu kara miru kindai bungobun no tsūjiteki henka. Nihongogaku Ronshū, $15,83-97$.

Konno, S. (2017). Kango jisho no kango. Seisen Joshi Daigaku Jinbun Kagaku Kenkyūsho Kiyō, 38, 129146.

Mochizuki, M. (2010). A study of "na" adjective with suffix "teki" and JSL teaching: Native and non-native compared. Journal of Foreign Language Studies, 2, $1-12$.

Murayama, M. (2019). Setsubiji -hashi (-washii) no hensen. Nihongo No Kenkyū, 15(2), 18-34.

Narikawa, Y. (2017). A guide for easy-to-understand Japanese sentences, contents and background of Kyodo News stylebook. Jōhō Kanri, 60(2), 69-78. https://doi.org/10.1241/johokanri.60.69.

Niess, J. (2016). Telling and selling: Literary fiction in early Malay language newspapers in colonial Indonesia. Wacana, 17(3), 377-403. https://doi.org/10.17510/ WACANA.V17I3.453.

Nurrochsyam, M. W. (2015). Persoalan pelestarian bahasa Ciacia: Refleksi atas etika diskursus. Jurnal Pendidikan dan Kebudayaan, 21(2), 153-166. https://doi.org/10.24832/jpnk.v21i2.183.

Ogura, Y. (2017). How to use indigenous words and Chinese loanwords properly in Japanese oral expressions. Ōsaka Daigaku Nihongo Nihon Bunka Kyōiku Sentā Jugyō Kenkyū, 15, 19-30.

Ortega, L. (2020). The study of heritage language development from a bilingualism and social justice perspective. Language Learning, 70, 15-53. https:// doi.org/10.1111/lang.12347.

Otsuka, T. (2019). Consideration and proposal on the suffix "teki" in Japanese dictionaries for elementary school students: A research of elementary and junior high school textbooks. Tsukuba Japanese Linguistics, 23, 60-82.

Raversa, A., \& Haristiani, N. (2020). Can Japanese speak in pure Japanese? The inevitability of gairaigo in Japanese. Advances in Social Science, Education and Humanities Research, 424, 175-180. https:// dx.doi.org/10.2991/assehr.k.200325.077.

Severin, A. A. (2017). Vigilance or tolerance? Younger speakers' attitudes to Australian English usage. Australian Journal of Linguistics, 37(2), 156-181. https://doi.org/10.1080/07268602.2017.1239521.

Sitokdana, M. N. N., Tanone, R., \& Tanaem, P. F. (2019). Digitalization of the local language dictionary of Pegunungan Bintang. Procedia Computer Science, 161, 49-56. https://doi.org/10.1016/j. procs.2019.11.098.

Sutjiati, N., \& Rasiban, L. M. (2018). The comprehension of Japanese culture in learning Japanese as foreign language. The Tenth Conference on Applied Linguistics and the Second English Language Teaching and Technology Conference in Collaboration with The First International Conference on Language, Literature, Culture, and Education, 1, 737-740.

Tajeddin, Z., \& Ghaffaryan, S. (2020). Language teachers' intercultural identity in the critical context of cultural globalization and its metaphoric realization. Journal of Intercultural Communication Research, 49(3), 263-281. https://doi.org/10.1080/17475759.2020.17 54884.

Takahashi, K. (2005). The suffix of -teki in Japanese. Kyōto Joshi Daigaku Eibun Gakkai, 49, 1-22.

Valdez, P. N., \& Flores, G. M. (2019). Language, politics, and economics in an era of globalization. Journal of Multicultural Discourses, 14(2), 188-194. https:// doi.org/10.1080/17447143.2019.1605965.

Wang, J. (2016). Functional and semantic changes of the suffix "-teki" treated in the dictionaries (Part 3). Heian Jogakuin University Journal, 16, 43-54.

Yamada, T., Shibata, T., Sakai, K., Kuramochi, Y., Yamada, A., Ueno, Z., Isshima, M., \& Sasahara, H. (2012). Shinmeikai kokugo jiten dai-nana-han. Tōkyō: Sanseidō.

Yashima, J. (2019). Teki no setsubiji fuka ni kan suru oboegaki. Jinbun Kagaku Nenpō, 49, 171-183. 